From the equation $R_{t}=R-R_{0}$, the target's component of the closing rate is obtained either mentally or by calculator. While the parameters governing own ship's component are known exactly those for $R_{\mathrm{t}}$ are not, and an infinite number of permutations of target course and speed exist to produce a given value for $R_{t}$. Nevertheless, the value of $R_{t}$ together with its algebraic sign yields valuable information and the ratio $R_{\mathrm{t}} / R_{\mathrm{o}}$ (from the calculator) provides a factor to be used in deciding the degree of avoiding action necessary to eliminate collision risk. The following is the basic concept:

If $R_{\mathrm{t}}$ is negative: I am 'overtaking' ship and must alter course to put the target at least $10^{\circ}$ on the opposite bow.

If $R_{t}$ is zero or nearly zero: Not forgetting the prevailing tidal stream the target is stationary; action is according to chart location and sea room.

If $R_{t}$ is positive: Target is inclined towards me and I must now assess and operate the ratio $R_{t} / R_{\mathbf{o}}$.

(i) If $R_{t} / R_{\mathrm{o}}$ is 1 or greater than 1 : Target's component being equal to or greater than my own, assuming target will take no avoiding action, my own action must be sufficient to eliminate or negate the gross rate.

Target to starboard: stop engines.

Target to port turn to starboard $\left(2 x \times R_{\mathrm{t}} / R_{\mathrm{o}}\right)$ degrees.

(ii) If $R_{\mathrm{t}} / R_{\mathrm{o}}$ is less than 1 : My own ship is generating most of the collision risk so that a proportionally smaller action on my part will eliminate the risk.

Target to starboard: reduce speed to $R_{\mathrm{t}} / R_{\mathrm{o}} \times$ present speed.

Target to port: turn to starboard $2 x \times R_{\mathrm{t}} / R_{\mathrm{o}}$ degrees.

In defining $x$ and $2 x$ I am quoting the turn advocated by the French Institute of Navigation (London meeting 1957), where $x$ is defined as the target's angle forward of the port beam and $2 x$ a turn to starboard of twice that angle. In plain language: turn to starboard until the target comes abeam to port, then continue the turn by the same amount again. A $2 x$ turn was at one time thought to be sufficient but a plot out of the example of target ' $B$ ' in Table I will show that this is not so. I prefer to define a $2 x$ turn as a 'standard' turn to be adjusted by the ratio $R_{t} / R_{0}$.

In conclusion, I would stress again that the measurement of 'rate' is in practice most accurate when collision risk is greatest, that is to say when the target on a relative motion display is seen to be closing on a radius cutting across the range rings at right angles. In practice I have found the principles described to work well enough for changes in bearing up to five degrees in two miles of closing range. Beyond that the accuracy in the measurement of rate falls away rapidly, but so too does the collision risk.

\title{
Education and the Sea
}

\section{W. J. Fifield}

Professor M'Pherson's paper on 'Education and the Sea'1 does somewhat less than justice to the non-university sector of the British educational system; his $A$ Ppendix $A$ lists only two university undergraduate courses in nautical/maritime 
studies, whereas six such courses are offered by polytechnics ${ }^{2}$ and the first of these was approved ten years ago.

More recent developments have included a B.Sc. in Fishery Science; a number of degree courses in Environmental Studies and Geography, which contain substantial elements of meteorology, oceanography, cartography and marine surveying; and post-graduate courses in Shipping Management and in Hydrographic Surveying. These courses gain awards of a first degree or the diploma of the Council for National Academic Awards-a body which deserves much credit for encouraging experimentation in many 'new' areas of study.

The polytechnics have grown from the larger (regional) Colleges of Technology and the work of these colleges, in the professional field, has underpinned the present developments in higher education in maritime studies. The staffs of these establishments are to be commended for many of the advances in nautical education made over the last two decades; the 'bread and butter' courses for M.N. officers, leading to certificates of Mate and Master, have proved useful starting points from which to expand.

No longer is entry to the courses that are offered restricted to students who actively serve at sea. An inspection of the prospectuses shows that ' $A$ ' level school leavers may be accepted on many of them, either as 'sandwich' students undertaking industrial experience in a branch of shipping, or in some cases as full-time students, who may or may not subsequently obtain employment in the maritime world.

To suggest as he does that 'the interest in marine subjects in the polytechnics and colleges of technology is no better than in the universities' is rather unkind to the former and perhaps flattering to the latter. The polytechnics in a relatively short life (less than a dozen years) have opened up a number of areas which are now included under maritime studies and have been foremost in introducing degree and diploma courses in nautical and fishery science-albeit that the universities have had something of a head start.

\section{REFEREN CES}

1 M'Pherson, P. K. (I 975). Education and the sea. This Journal, 28, 232.

2 Council for National Academic Awards, Annual Report, 1972-73, 24.

\section{Automatic Radar Plotting Systems}

$$
\text { Captain F. J. Wylie, O.B.E., R.N.(ret) }
$$

If I may continue Mr. Harrison's analogistic extravaganza 1 for only a moment, I would like to say that whatever smoke, haze or fog there may have been in his vicinity it has prevented him from identifying the target at which I and my colleagues have been firing. I must also say that his bland assumption of the superiority of his own gunnery is hardly complimentary to the highly qualified and experienced support without which, as he well knows, no simple sailor would venture into such a technical action.

None of my comments made upon this subject thus far have denied the exis- 